\title{
LA LEY ORGÁNICA 5/2012, DE 22 DE OCTUBRE, UNA BUENA REFORMA EN UNA BUENA DIRECCIÓN DEL RÉGIMEN DE FINANCIACIÓN DE LOS PARTIDOS POLÍTICOS
}

\author{
José María Coello de Portugal \\ Profesor Ayudante Doctor de Derecho Constitucional \\ Universidad Complutense de Madrid \\ jmcoello@ucm.es
}

\section{INTRODUCCIÓN: LA RECIENTE PROMULGACIÓN DE LA LEY ORGÁNICA 5/2012, DE 22 DE OCTUBRE}

El pasado día 23 de octubre de 2012, el Boletín Oficial del Estado anunciaba la penúltima reforma del régimen jurídico de la financiación de los partidos políticos en España mediante la publicación de la Ley Orgánica 5/2012, de 22 de octubre, de reforma de la Ley Orgánica 8/2007, de 4 de julio, sobre financiación de los partidos políticos. Esta reforma no tendría mayor importancia si no es porque la nueva disposición implica un temprano - y necesario - endurecimiento de algunas de las condiciones de financiación de los partidos políticos, recientemente aprobadas en la Ley Orgánica 8/2007, de 4 de julio. Temprana reforma que permite constatar la manifiesta insuficiencia de los controles jurídicos que en su día se establecieron por el legislador en materia de financiación de partidos a través de la citada Ley Orgánica 8/2007, junto con la sana voluntad de proceder a su enmienda. En realidad, la nueva norma se promulga con la bien pensada excusa de adaptar la financiación de los partidos políticos al actual contexto de crisis económica, entendiendo que «los partidos políticos, como principales instrumentos de representación política, participan en el esfuerzo colectivo necesario para superar la crisis» ${ }^{1}$. Medida legislativa, desde luego, importante y que reduce la cuantía de las subvenciones a los partidos - así como a las asociaciones y fundaciones vinculadas a éstosen un nada despreciable 20 por 100 respecto del ejercicio presupuestario anterior, pero que, sin embargo, no constituye la principal aportación de la

1 Texto del Preámbulo de la Ley Orgánica 5/2012, de 22 de octubre, de reforma de la Ley Orgánica 8/2007, de 4 de julio, sobre financiación de los partidos políticos. 
ley. Siendo la anterior una importantísima medida cuantitativa ampliamente difundida por los medios de comunicación — que la nueva ley se apresura a precisar que no afecta al principio de suficiencia de medios, sino que únicamente lo compatilibiza con el principio de austeridad-, la misma no constituye, ni de lejos, la principal novedad cualitativa de la reforma; al menos desde la óptica del jurista.

\section{EL VALOR POLÍTICO DE UN CONSENSO FUNDAMENTAL}

Tratándose de una disposición orgánica y según prevé la Constitución, la votación final sobre el conjunto del proyecto presentado por el gobierno ha cosechado en sede parlamentaria un significativo número de apoyos que arrojan unos datos bastante clarificadores acerca del sustancial consenso existente entre las fuerzas políticas con representación parlamentaria en relación con la necesidad de acometer la reforma del régimen legal de financiación de los partidos, así como con la orientación general seguida en la misma. La reforma resultó apoyada en el Congreso de los Diputados ${ }^{2}$ por 308 votos a favor (uno de ellos telemático), 2 en contra y 12 abstenciones, de los 322 votos emitidos, y en el Senado ${ }^{3}$, con una mayoría aún más amplia, por 215 votos a favor y 3 en contra de los 218 votos emitidos por sus señorías. Se trata, por tanto, de una reforma consensuada cuyos sólidos apoyos parlamentarios merecen ser puestos en valor en términos democráticos, especialmente en momentos como los actuales de fuerte contracción económica, en los que a las fuerzas políticas parece estar costando tanto alcanzar consensos parlamentarios.

\section{LAS NOVEDADES OCULTAS DE UNA LEY}

En primer lugar, merece destacarse muy positivamente la promulgación de una especie de incorporación general al régimen jurídico informador de la financiación de los partidos políticos en España de todas sus asociaciones y fundaciones vinculadas ${ }^{4}$. Entidades que, sin duda, cum-

\footnotetext{
${ }^{2}$ Diario de Sesiones del Congreso de los Diputados, X Legislatura, año 2012, núm. 46, Sesión plenaria núm. 45, celebrada el jueves 28 de junio de 2012, p. 54.

3 Diario de Sesiones del Senado, X Legislatura, año 2012, núm. 34, Sesión plenaria celebrada el 10 de octubre de 2012, p. 2389.

${ }^{4}$ El Proyecto de Ley de Presupuestos Generales del Estado para 2013, en el actual
} 
plían un importante fin como laboratorios de ideas políticas y de bisagra entre la estructura orgánica de los partidos y la sociedad civil, pero que, sin duda también, en muchas ocasiones actuaban como sumideros de la eficacia normativa de la vieja ley para - de una forma legal pero dudosamente ética- eludir las disposiciones en vigor en materia de financiación y aceptar aquellos recursos que el partido político, por muy diversas razones, no se encontraba en situación legal de aceptar. Decidida inclusión en la ley del control jurídico de la financiación de asociaciones y fundaciones vinculadas que implica una plausible aportación del legislador, que esperemos que en el futuro impulse la transparencia en la estructura financiera de los partidos políticos mediante la consolidación en su régimen de control de las cuentas de sus asociaciones y fundaciones vinculadas.

En segundo lugar, la incorporación de las asociaciones y fundaciones «políticas» al régimen jurídico de financiación de los partidos a los que asisten implicará, probablemente también, una disminución de las prácticas ilegales mediante la ampliación del número de sujetos que tienen, desde ahora, vetada la posibilidad de aportar recursos financieros a estas fundaciones políticas al ser perceptores de fondos procedentes de las Administraciones Públicas. De este modo — que sin duda llega tarde a nuestro ordenamiento jurídico, pero por cuya llegada todos debemos felicitarnos- se impermeabilizan algunas de las grietas del poder público, como son las ayudas y subvenciones que recibían algunas de estas fundaciones procedentes de las entidades empresariales ${ }^{5}$ perceptoras de fondos públicos. Con ello se elimina, o al menos se reduce, la permanente tentación de los poderes administrativos de resolver en el ejercicio de su actividad concesional y subvencional no ateniéndose a estrictos criterios de persecución del interés general, sino de simpatía política o, peor aún, de

Estado de su tramitación parlamentaria, prevé la financiación pública de estas entidades, además de por otros ingresos que pudieran percibir, con 2,9 millones de euros; aportados dos de ellos por el presupuesto del Ministerio de Educación, Cultura y Deporte (sección 18) «a fundaciones y asociaciones con dependencia orgánica de partidos políticos con representación en las Cortes Generales, para funcionamiento y actividades de estudio y desarrollo del pensamiento político, social y cultural», y 900.000 euros más por el Ministerio de Asuntos Exteriores y de Cooperación.

5 «Es evidente que los dirigentes de la economía no tienen sólo a su disposición en la democracia política el volumen de poder político que le dan sus votos. Con bastante frecuencia pueden adquirir una posición política dominante. El poder del capital les permite dirigir la opinión pública de modo indirecto, valiéndose de las cajas de los partidos y de los periódicos, del cine, de la radio y de otros muchos medios de influir en las masas, con lo cual adquieren un enorme poder político» [H. HelleR, Teoría del Estado, México, Fondo de Cultura Económica, 1998 (2. ${ }^{a}$ reimpr., 2002), p. 180]. 
previsible generosidad con el partido de cada una de las empresas privadas perceptoras de fondos públicos. Práctica que, si bien —afortunadamente- no era frecuente en nuestra Administración Pública, sí podía situar bajo sospecha a los dirigentes políticos que en el marco de sus responsabilidades de gobierno - no de partido- concedían las mismas, así como también generar infundados recelos respecto de las empresas o entidades privadas perceptoras de estos fondos públicos.

En tercer lugar, en términos de calidad democrática, debe también ser destacado el cegamiento por el legislador de otro de los tradicionales sumideros de la normatividad de las leyes de financiación, como han sido las condonaciones de deudas, prohibiéndose desde ahora a todas las entidades de crédito la condonación a cada partido político de cantidades superiores a los cien mil euros anuales. Prohibición legal que pretende poner coto a la generalizada práctica ${ }^{6}$ —especialmente lacerante en el actual contexto de crisis económica en que las entidades financieras no se caracterizan por su benevolencia con el ciudadano- de donaciones encubiertas a estas formaciones mediante la remisión de débitos, previa solicitud por el partido de un crédito a la entidad condonante, casi siempre consciente de su imposible devolución. Práctica rayana en lo socialmente escandaloso que encubría hasta ahora una forma de financiación estable - puede que legal, pero seguro que inmoral- de los partidos políticos, así como generadora de la permanente tentación para las fuerzas políticas de tener una especial consideración con las entidades financieras bancarias desde el ejercicio del poder público ${ }^{7}$.

En cuarto lugar, la nueva ley ha adoptado algunas medidas de refuerzo del principio de transparencia en la buena dirección, concretadas en la imposición a los partidos de nuevas obligaciones de publicidad y notificación. Se obliga, por ejemplo, a comunicar al Tribunal de Cuentas en

${ }^{6}$ Cuestión largamente reclamada por la doctrina. Así, se señalaba: «A la vista de esta historia, resulta razonable concluir que, en bien de todos — de los partidos, de los bancos y cajas, pero también y sobre todo de la limpieza del proceso democrático- hay que poner límite al endeudamiento y depurar las prácticas crediticias de los partidos» (G. ARIÑO OrTiz, La financiación de los partidos políticos, Col. Foro de la Sociedad Civil, Madrid. Cinca, 2009, p. 61).

${ }^{7}$ «Para lograr que los partidos efectivamente concurran a la formación de la voluntad popular, sin verse atados a los intereses de quienes les sustenten económicamente una vez que hayan alcanzado la representación parlamentaria o, en su caso, el gobierno, ha de asegurarse su independencia económica de manera que sus ingresos no procedan exclusiva o predominantemente de quienes pretendan verse de algún modo recompensados» (M. HoLGADO GonzÁlez, La financiación de los partidos políticos en España, Valencia, Tirant lo Blanch, 2003, p. 35). 
el plazo de tres meses toda donación recibida en cuantía superior a cincuenta mil euros, así como aquellas que consistan en bienes inmuebles de cualquier clase. Del mismo modo que se impone también a los partidos la obligación de puesta en conocimiento de este órgano fiscalizador de las cuentas públicas de todas las condonaciones de deuda que hubiesen recibido, de las que también se debe desde ahora dar cuenta al Banco de España como Administración de control de las entidades financieras. Deberes de información que se completan con la, también nueva, obligación de notificar al Tribunal de Cuentas todas las donaciones que se hubiesen recibido por las fundaciones vinculadas a los partidos políticos, cuyos donantes fuesen personas jurídicas.

En quinto lugar, en el plano orgánico debe también valorarse muy positivamente el refuerzo que la nueva ley pretende hacer del papel del Tribunal de Cuentas como supremo órgano fiscalizador de las cuentas del Estado y, por tanto también, «sobre la gestión económico-financiera del partido político» —en los términos empleados por la nueva ley- ${ }^{8}$, obligando a las fundaciones de los partidos a publicar lo esencial de su información contable. Posición del Tribunal de Cuentas que, en consonancia con lo previsto por la Constitución, se ve reforzada mediante la atribución competencial indubitada - hasta ahora francamente confusa en su alcance- para la imposición de sanciones a los partidos por la comisión de infracciones muy graves derivadas del incumplimiento de lo dispuesto en la propia Ley Orgánica 8/2007, de 4 de julio, sobre financiación de los partidos políticos, en relación con la aceptación de donaciones ilegales, la falta de presentación o presentación defectuosa de cuentas anuales, o por el incumplimiento de las previsiones de la Ley Orgánica 5/1985, de 19 de junio, del Régimen Electoral General, en materia de superación de los límites de gastos electorales ${ }^{9}$. Potestad sancionadora concedida al Tribunal de Cuentas que expresamente se determina por la nueva ley como compatible con la exigencia de cualesquiera otras responsabilidades jurídicas en que se pudiera incurrir relativas a la financiación de partidos políticos.

8 Art. 8 de la Ley Orgánica 5/2012, de 22 de octubre, de reforma de la Ley Orgánica 8/2007, de 4 de julio, sobre financiación de los partidos políticos, mediante el que se modifica el texto del art. 18 de la ley reformada.

9 «Este último aspecto del problema es fundamental: toda campaña electoral representa un gran gasto. La técnica del partido de masas tiene como efecto sustituir al financiamiento capitalista de las elecciones con un financiamiento democrático» (M. DUverger, Los partidos políticos, Madrid, Fondo de Cultura Económica, 2002, p. 93). 
Por último, en el plano de lo funcional debe valorarse también positivamente el señalamiento de la ley —aunque sea todavía como mera recomendación - de las nuevas tecnologías como instrumento preferente para que los partidos políticos hagan efectivo el cumplimiento de sus obligaciones de transparencia y publicidad a través de sus páginas web. Recomendación del legislador que, si bien no ha dado el paso decisivo de convertir en obligatoria esta difusión on line de los principales datos de financiación, supone un paso que también abunda en la buena dirección y en la transparencia del partido ante los ciudadanos mediante el establecimiento - todavía voluntario- de un canal de acceso real y efectivo a sus principales datos financieros, que intuimos que las formaciones políticas pondrán en marcha sólo a medida que la opinión pública se lo vaya demandando.

\section{VALORACIÓN JURÍDICA DE UNA NORMA, VALORACIÓN POLÍTICA DE UNA REFORMA}

a) Estructuralmente clarificadora--Lo primero que debe destacarse de la nueva Ley Orgánica 5/2012, de 22 de octubre, al menos desde la perspectiva del jurista, es su carácter clarificador del ordenamiento jurídico respecto del alcance de las competencias de fiscalización y sanción del Tribunal de Cuentas en materia de control financiero de los partidos políticos. Ahora sólo falta ya que, tomando ejemplo de esta nueva disposición, la jurisdicción de este órgano de relevancia constitucional se aclare en su legislación propia con carácter general y, de una vez por todas, se aclare el alcance de los poderes y la jurisdicción del supremo órgano fiscalizador de las cuentas del Estado. Cuestión sobre la que, por su poca claridad -y puede que por el poco interés en su aclaración-, han corrido ríos de tinta en la doctrina jurídica española, siendo una de las virtudes de esta ley, por tanto, su carácter estructuralmente clarificador del ordenamiento jurídico en esta sensible materia.

b) Técnicamente depuradora.-La expresión técnica de la nueva ley también es, a nuestro entender, digna de elogio desde el punto de vista de la técnica legislativa; cosa a la que el legislador, lamentablemente, no nos tiene siempre acostumbrados. Y lo es en un doble plano. Se trata, por una parte, de una norma que, más que innovar el ordenamiento jurídico, viene a depurarlo, aclarando los aspectos competenciales a los que nos hemos referido, así como a combinar una reforma de largo alcance que, sin embargo, se realiza a través de un texto inusualmente breve. De otro 
lado, la nueva ley dedica buena parte de sus esfuerzos a la tarea de facilitar la interpretación del texto resultante, no limitándose simplemente a reformar, sino a reformular con acierto técnico la norma anterior, eliminando del texto reformado aquellos preceptos que pudiesen resultar confusos ${ }^{10}$ - cosa de la que el legislador tiende frecuentemente a olvidarse- o, incluso, alterando, a resultas de la nueva redacción, no sólo el tenor literal de los preceptos de la ley reformada, sino también su sistemática, de forma que en ocasiones no se cambia el texto pero sí, por ejemplo, la numeración de preceptos que no se eliminan pero que, aun manteniendo su tenor literal, se alteran en su sistemática, en coherencia con la nueva legislación ${ }^{11}$. Precisión técnica que merece ser positivamente valorada y que, sin duda alguna, coadyuvará a evitar problemas interpretativos de la reforma.

c) Políticamente consensuada.-Otro de los indudables méritos de esta reforma se refiere al alto grado de consenso parlamentario con el que ha contado en su tramitación. Acuerdo entre fuerzas políticas que debe ser puesto en valor por un doble motivo: en primer lugar. por su carácter ciertamente excepcional en el actual contexto político, y, en segundo lugar, por la vida relativamente larga que cabe augurar a esta importante reforma en relación con el marco jurídico de la financiación de los partidos políticos en España. Se trata, por tanto, de una reforma demandada por la sociedad española cuya necesidad ha sido comúnmente apreciada por nuestros representantes y, finalmente, ampliamente consensuada y apoyada por casi todas las fuerzas políticas con representación parlamentaria.

d) Sustancialmente regeneradora._La reforma promulgada significa un cambio bastante más estructural de lo que pudiera parecer tras una lectura poco atenta de su texto. Si bien no se reforman los principios informadores del sistema de financiación, ya presentes con acierto en la ley reformada, sí se han adoptado por el legislador una serie de iniciativas que concretan mejor esos principios y tienden a erradicar algunas de las prácticas menos confesables de los partidos en materia de financiación, difícilmente compatibles con las exigencias de la transparencia democrática. En estos términos, pese a que la nueva ley parece únicamente adoptar un conjunto de medidas concretas, su vocación va mucho más allá, con un espíritu que podríamos calificar como bienintencionadamente regenerador de

${ }^{10}$ Es el caso de lo previsto en el art. 13 de la Ley, que suprime la disposición transitoria segunda del antiguo texto.

${ }_{11}$ Es el caso del art. 15 de la Ley, por el que, sin cambiar en nada su texto, la anterior disposición final única de la reformada Ley Orgánica 8/2007, de 4 de julio, se mantiene, pero pasando ahora a ser la nueva disposición final primera del texto reformado. 
una importante faceta de la vida democrática. Regeneración fuertemente demandada por la opinión pública que profundiza en la buena dirección y que redundará, sin duda, en una mejora de la calidad democrática ${ }^{12}$ y de la praxis de los partidos políticos en materia financiera.

e) Coyunturalmente moderadora.-Finalmente $-\mathrm{y}$ sin que esta medida sea la de mayor trascendencia en la nueva norma- la opinión pública ha valorado, en términos generales muy positivamente, el hecho de que las fuerzas políticas más representativas hayan aplicado a sus propias cuentas y actividades - como el resto de los agentes sociales- un coyuntural pero ciertamente extraordinario esfuerzo presupuestario de austeridad y de racionalización del gasto, aceptando una reducción de veinte puntos porcentuales de su financiación pública. Gesto que, además de permitir la aplicación de esa importante partida presupuestaria a fines socialmente más urgentes en el actual contexto de crisis económica, permitirá una sana autocrítica en todas las organizaciones políticas acerca del empleo de los recursos de los que disponen de forma estable para el sostenimiento de sus actividades y la persecución de sus trascendentes fines constitucionales.

12 «La democracia moderna descansa, puede decirse, sobre los partidos políticos, cuya significación crece con el fortalecimiento progresivo del principio democrático» (H. KELSEN, Esencia y valor de la democracia, Comares. Granada, 2002, p. 24). 